RESEARCH AND PRACTICE

\title{
Context matters: A community-based study of urban minority parents' views on child health
}

\author{
Cassandra L. Bolar, PhD, Natalie Hernandez, PhD, MPH, Tabia Henry Akintobi, PhD, MPH, Calvin McAllister, MPH, \\ Aneeqah S. Ferguson, MS, Latrice Rollins, PhD, Glenda Wrenn, MD, Martha Okafor, MD, David Collins, and Thomas Clem
}

Satcher Health Leadership Institute and Prevention Research Center, Morehouse School of Medicine, Atlanta, GA

\begin{abstract}
Background: Among children, there are substantial ethno-racial minority disparities across a broad range of health-related behaviors, experiences, and outcomes. Addressing these disparities is important, as childhood and adolescence establish health trajectories that extend throughout life.

Methods: The current study employed a community-based participatory research approach to gain community insight on child health priorities and to frame an intervention aimed at improving the health of minority children. Eight focus groups were conducted among seventy-five African American parents in a Southeastern city. The current study was guided by an ecological theoretical framework.

Results: Although the focus of this investigation was on community identification of child health priorities, participants cited, as root determinants, contextual factors, which included lack of healthy food options, lack of spaces for physical activity, and community violence. These co-occurring factors were related to limited engagement in outdoor activities and physical activity, increased obesity, and poor mental health and coping. Poor parenting was cited as the most substantial barrier to improving child health outcomes, and quality parenting was identified as the most important issue to address for community programs focused on promoting the health and success of children. For improving health outcomes for children in their neighborhoods, establishment of positive social capital and constructive activities were also cited.
\end{abstract}

Conclusions: These results reinforce social determinants of health as influences on child health outcomes and describe how community engagement can address potential solutions through interventions that resonate with program participants.

Keywords: child health disparities, minorities, environmental influences, parenting

\section{INTRODUCTION}

Inequities in the access to healthcare across different racial, ethnic, socioeconomic status (SES) and education groups contribute to health disparities and are found within all age groups, including adolescents and young children (National Institute for Health Care Management, 2007). Recent data suggest that the United States is failing to make substantial progress towards the Healthy People 2020 overarching goal of achieving health equity and eliminating health disparities (U.S. Department of Health and Human Services, 2014). Minority children with lower SES suffer disproportionately from diseases and experience higher rates of mortality than those with higher SES (National Institute for Health Care Management, 2007). In regard to childhood obesity, ethnoracial disparities are evident as early as the preschool years (Taveras, Gillman, Kleinman, Rich-Edwards \& RifasShiman, 2013). For example, the National Health and Nutrition Examination Survey (2003-2006) found that $10.7 \%$ of non-Hispanic White children, $14.9 \%$ of nonHispanic Black children, and $16.7 \%$ of Mexican-American children of ages 2 through 5 years had body mass index values $\geq$ the 95th percentile (Ogden, Carrol, \& Flegal, 2008). Further, African American children in low-income communities are particularly susceptible to being overweight (Ogden, Troiano, Briefel, Kuczmarski, Flegal, \& Johnson, 1997). These findings highlight the need for interventions, among minority children, to reduce health disparities, in particular, childhood obesity.

\section{Social Determinants of Health and the Ecological Theory}

The inclusion of social determinants of health - the conditions in which people are born, grow, live, and work in the discourse on health disparities provides insight on the salient role of context in predicting individual health outcomes. Considering the influence of parenting on children's health, in tandem with social determinants of health, is appropriate due to the position parents have in shaping the environment of their children. Ecological Theory provides a helpful framework for delineating the mechanisms by which parenting interplays with social determinants of health to affect the overall health and wellbeing of children. According to Ecological Theory (Bronfenbrenner, 1979), contextual factors influence the behaviors and beliefs of individuals on various levels: directly through interactions in the microsystem (parents, family members, school, friends, and community organizations) and indirectly through interactions in the mesosystem (relations between microsystems), exosystem 
(social context), macrosytem (cultural context), and chronosystem (changes in contextual systems over time). Additionally, individual characteristics (e.g., personality, temperament) determine the influence of environmental factors (Bronfenbrenner, 1979). In reference to children's health, individual factors innate to each child, such as genetic predisposition, have implications for children's health. Within the microsystem, parents shape various familial norms related to nutrition and physical health. They influence the mesosystem and exosystem by facilitating the child's personal and social relationships with family, friends and the immediate community. Parents also negotiate and provide boundaries for the degree to which various microand mesosystems interact and have access to their children. Overall, parenting serves as an important mediator for the influence of context on children's health and well-being.

\section{Quality Parenting as a Protective Factor}

For children who are at risk of experiencing health disparities and/or other adversities; support from a caring parent or adult serves as a protective factor (Mistry, Benner, Biesanz, Clark, \& Howes, 2010; Whittaker, Jones-Harden, See, Meisch, \& Westbrook, 2011). According to the Administration on Children, Youth and Families (2012), protective factors "buffer" the effects of risk exposure and may help individuals and families negotiate difficult circumstances and children to perform better in school and other social activities. Quality parenting includes establishing clear standards and limits; utilizing positive discipline strategies; engaging in positive, supportive interactions; understanding child development; and providing proper healthcare. These parenting strategies concern, acceptance, and support from a caring parent or other adult - promote resiliency in children (Rutter,1985).

For children, quality parenting is associated with higher self-esteem, lower risk of antisocial behavior, better social skills and psychological adjustment, and a lower incidence of internalizing behaviors (Children's Bureau, 2012; Davidov \& Grusec, 2006; Rutter, 1985), many of which are the same for children who remain resilient in the face of adversity (Rutter, 1985). Additionally, quality parenting enhances physical health of children, promotes physical well-being, and improves the prognosis for chronic diseases (Darling \& Steinberg, 1993). Overall, children who experience chronic adversity fare better and recover more effectively when they have a positive relationship with a competent adult - they are better learners and problem solvers, more interactive with others, and have areas of competence and perceived efficacy that hold intrinsic value (Masten, Best, \& Garmenzy, 1990).

\section{Current Study}

An iterative community-based participatory approach was utilized to identify health inequalities and diseases that could be addressed through a parenting intervention. Community-based participatory research (CBPR) emphasizes an equal partnership, power sharing in decisionmaking, and data ownership between community and academic partners (Jones \& Wells, 2007). Among the advantages of CBPR are strengthened neighborhoodcampus relationships, improved research question relevance, enhanced research recruitment and implementation, collective dissemination, and mutual benefits for a diverse group of stakeholders (Cargo \& Mercer, 2008; Jagosh et al., 2012; Seifer, 2006). Such a partnership can foster involvement of community members in the development, implementation, and evaluation of programs that address health disparities among children. The collaborative approach enables the creation of interventions that are tailored to the weighty needs of a community and to existing resources.

The overall goal of this research effort was to develop and implement a community-driven plan for reducing health disparities among resource-limited, minority children and their families. The Morehouse School of Medicine Prevention Research Center and the Satcher Health Leadership Institute collaborated to develop a formative research approach that built upon their previous efforts in CBPR and in development of peer-to-peer parenting interventions. Partner communities were comprised of Metropolitan Atlanta Neighborhood Planning Units (NPUs). The City of Atlanta is divided into twenty-five NPUs, within which citizen advisory councils represent community leadership through which to partner in developing and implementing interventions. Partner NPUs (V, X, Y, Z, T, and L) are characterized by poverty, a lack of neighborhood resources, and chronic diseases. For these NPUs, the residents are mostly African American (88\%); young (median age, 30); and poorly educated (26\% of adults did not complete high school). The total population is 73,281 . The median household income is $\$ 27,276$, and $27 \%$ of all households receive food stamps (U.S. Census, 2006-2010).

To ensure a CBPR approach, a community-majority governing body (composed of residents of partner NPUs) was developed. This board was created to espouse community relevance, ownership and research rigor in implementation. The board's positioning of NPUs as senior partners included their leadership as chair, co-chair, and secretary of the board.

\section{METHODS}

Eight focus groups were conducted between April and May 2014 at community-based organizations within the targeted NPUs in Metropolitan Atlanta. Through established relationships with community-based organizations, participants were recruited at these sites. These settings, identified by community members, serve predominantly urban, low-income, African American parents. Participants who received services from these sites were recruited by staff, the project coordinator, and community residents. In addition, participants were recruited through flyers, referrals, and word of mouth. Seventy-five African American residents (58 females, 11 males, and 6 with gender unknown) who resided within the targeted NPUs and met eligibility criteria (African American adult parent or caregiver) participated in the focus groups. No identifiable information was collected during the focus group sessions. In addition, participants were informed that the discussion would be recorded. Refreshments were provided and, at the conclusion of the focus groups discussions, participants 
were remunerated for their time. The study was approved by the Morehouse School of Medicine Institutional Review Board.

Focus groups were conducted by project staff experienced and trained in leading such groups. Standard moderation techniques were used (Krueger, 1998). All discussions lasted between 1 to 2 hours and were audiotaped and transcribed verbatim. Focus groups discussions continued until data saturation, theoretical saturation, and informational redundancy were achieved (Sandelowski, 1995). The focus group guide, which was semi-structured and open-ended, used probes to ensure that relevant issues were covered adequately. The interview guide explored the following areas: a) viewpoints on issues influencing children's health, including community-level changes that may have an influence on children's health and concerns regarding children's health; b) viewpoints of children's health priorities, including factors that prevent children in the community from being healthy; and c) priority areas for community programs that address children's health. A community advisory board, which consisted of residents from the target population, reviewed the focus group guide to ensure that the questions were unbiased, objective, culturally-relevant, and written at a universal reading level. Several revisions were made to meet the prescribed objectives of the advisory board. The guide was piloted to test for appropriateness of questions and language accuracy.

Data were managed using NVivo qualitative data analysis software version 10. Analysis was guided by a Grounded Theory approach, allowing categories, themes and patterns to emerge (Strauss \& Corbin, 1998). Two reviewers independently identified primary coding categories using the issues probed, followed by reconciliation of the codes to produce a single coded transcript. Discrepancies were discussed based on the transcript language and code definitions until agreement of the assigned code was achieved.

\section{RESULTS}

\section{Community Level Changes Influencing Child Health}

Lack of Healthy Food and Physical Inactivity. Although parents were asked to identify positive and negative community-level changes that have influenced children's health, parents identified only negative changes. Most of the participants identified contextual factors as the root determinants of children's health, including the absence of basic resources, such as lack of healthy food and constructive engagement of children, including physical activity. Many participants agreed that accessing healthy food was a challenge and mentioned that, in their communities, there were no supermarkets but many fastfood restaurants and convenience stores. Although the convenience stores sold food, they lacked healthy, highquality foods as illustrated in the following excerpt:

Most of our convenient stores in the neighborhood the kids can run to, they don't sell nothing healthy for children. Most of them is falling down. Time the child hit the door, the first thing he see is sugar. Ain't no fruits in them stores. Ain't nothing healthy now, and we don't say nothing about it.

For children, some parents identified obesity and overweight as an issue but most agreed that the larger issue was physical inactivity. Participants mentioned that there were few physical activity resources such as recreational facilities, making it difficult for their children to lead an active lifestyle. In addition, some mentioned that they would rather have their children play video games inside than play outside where there is crime and lack of safety. A few discussed limited opportunities to play. Some conversed about cuts to recess and physical education. Many agreed that their children are not getting physical education at school, which is contributing to their children being overweight. One parent said, "We had physical education. They took that out of school. They need to bring that back in the school."

Community Violence. A frequently discussed communitylevel change was increased violence. The most common types of violence mentioned during the focus groups were fights among gangs and other groups and shootings. Participants recognized the rise in gang activity and shootings in their neighborhoods and described how it had compelled them to change their lifestyles. Some participants revealed how they or their children were direct victims of the community violence, as illustrated by one parent, "It came - (the bullet) ricocheted in the room. I still had my baby on this side, and it hit me right here. And that was shot from... all the way across the field, and that was an AK.”

\section{Priority Components of Community Interventions that Address Child Health}

Improved Parenting Skills and Involvement. Social factors such as poor parenting skills and low or limited parental involvement were identified as issues to address by interventions that relate to child health. Some participants mentioned that many parents in their communities were not fully present, especially emotionally, in their children's lives. Participants also felt that there was a lack of parental concern for their children's general well-being and specifically for their health. They gave examples of children sent to school even though they were sick, children not dressed appropriately for the weather, children with poor hygiene, and children not getting enough sleep or food. One parent, who was also an early childcare provider, indicated the following:

They bring the kids in. Their eyes are boiling red, and you're asking the parents, you know, what's going on with their eyes, you know, did you take them to the doctor? "No, no." Then the child wakes up and have all this green stuff floating, and you're telling them, you know, that's the symptom of pink eye, and they're like "No it's not. They're okay." You know they don't want to take your concern, you know, what the teacher say is not 
really important when it comes to them being sick cause they don't want them to have to stay home.

Some participants related lack of parental involvement to those who do not know how to parent effectively or who are preoccupied with other things. They felt that parents are often unable to pay attention to parental care. One participant said: "I think it should be more parents involved. Nowadays they so caught up in the materialistic stuff like people are so in competition instead of trying to teach your child to go outside and play.”

Other participants mentioned that there is a general lack of resources and information available to parents to help them improve their skills. One said: "But you know what parenting workshops are good too because I don't care if you're a millionaire, you still don't know what to do with the first one."

Some participants pointed to the high number of young parents in the community who, they believe, are not only lack parenting skills and knowledge but have co-occurring challenges reflecting their own development into adulthood. This subgroup of parents was positioned among those who need individualized programs to address their unique needs. As illustrated by one participant,

We have too many young parents, too many teenaged parents. And they're not apparently either willing to follow through. They don't have anyone really pushing them like a parent or something, and so there needs to be something done to help...because we're having too many young mothers raising children. And they're not mature. They don't know what to teach them cause they're not mature.

Mental Health and Coping. Another priority area cited by most participants was the issue of mental health, or, as some participants called it, “a good mind”. Respondents felt that some poor mental health or coping issues were in response to chronic exposure to community violence. One participant described this issue as follows:

So, now you're dealing with the mental health aspect of it. And all it takes is a few minutes just dealing with the children and things that they seeing and experience and just see where they at mentally. And a lot of times they've seen stuff and heard stuff and been a part of stuff that they're just not meant to be ready for, and it has that impact on it. You talking about you see a story on the news where somebody is kidnapped and held, but then they don't tell the story about the child that lived next to that and then the police coming in the middle of the night waking them up out their sleep making a lot that noise, you know, and seeing a raid. You hear somebody get shot, but nobody say about the children that saw that shooting. And over time, that stuff weighs on these children mentally.
Many stated that they feel depression among adults was an issue in their community and that it has an impact on children. Participants expressed what they perceived as lack of bonding and affection among parents and children. Some believed that some child neglect could be associated with parental depression. Others felt that parents oftentimes take out their unresolved issues, translating mental health coping and related stressors, on their children. This is how one participant stated that notion:

Like my mamma told me, she said girl depression don't exist in your family. You better get over it. You better get up. You better, you know, just deal with it, and the fact of the matter is because we don't deal with those issues, we take it out in the worst way possible. And we don't even realize that we're hurting our children cause that's all we know.

\section{Community Conditions Needed for Children to be Healthy and Successful}

Positive Social Capital. Establishing positive community social capital and constructive activities for children were cited as necessary to promoting their success. Many participants felt that a positive sense of community could improve the health of children. They mentioned that if everyone worked together or if there were a shared community responsibility for children, the health of their children would improve. Lack of respect and accountability were values that were missing in the community. One participant said: "You need to -- everybody want to encourage each other. Everybody say encourage each other, but you have to do it. I'm one of those persons.”

Parental and Adult Involvement. Positive parental and adult involvement was identified as the most relevant solution for improving children's health. This was the most consistently cited solution, and, as mentioned previously, poor parenting was identified as the leading barrier to promoting the optimal health and well-being of children. Respondents expressed that communities typified as having highly engaged parents and adults are best for positive child health outcomes for children. Participants expressed that they feel children need parents who care and are actively involved in their children's lives. Several felt that children need love and role models. One participant stated: "The number one thing they need is a parent that cares."

Community Spaces for Physical Activity and Constructive Child Engagement. A reoccurring theme throughout the focus group discussions was the limited access and availability of activities and afterschool programs for children. Participants stated that they wanted their children to be more involved but felt that there were not enough constructive outlets for physical activities in their communities. A few mentioned that this may be attributed to the fact that there are not enough places for children to be active. One participant stated: "I think they need to have a place for the children to go exercise and go do some positive things. Like little gyms and have something to do because it's really nothing for these children to do." 


\section{DISCUSSION}

There is theoretical and empirical support for the integral role played by the environment in affecting individual wellbeing and health outcomes (Brofenbrenner, 1979; Koskenvuo \& Koskenvuo, 2015; Rossen, 2014). The current results corroborate previous findings by highlighting the effects that the environment has on the health of children. Figure 1 is a conceptual model depicting respondents' perceptions of community-level changes influencing children's health and priority areas for child health interventions; their responses are positioned within the framework of Ecological Theory.

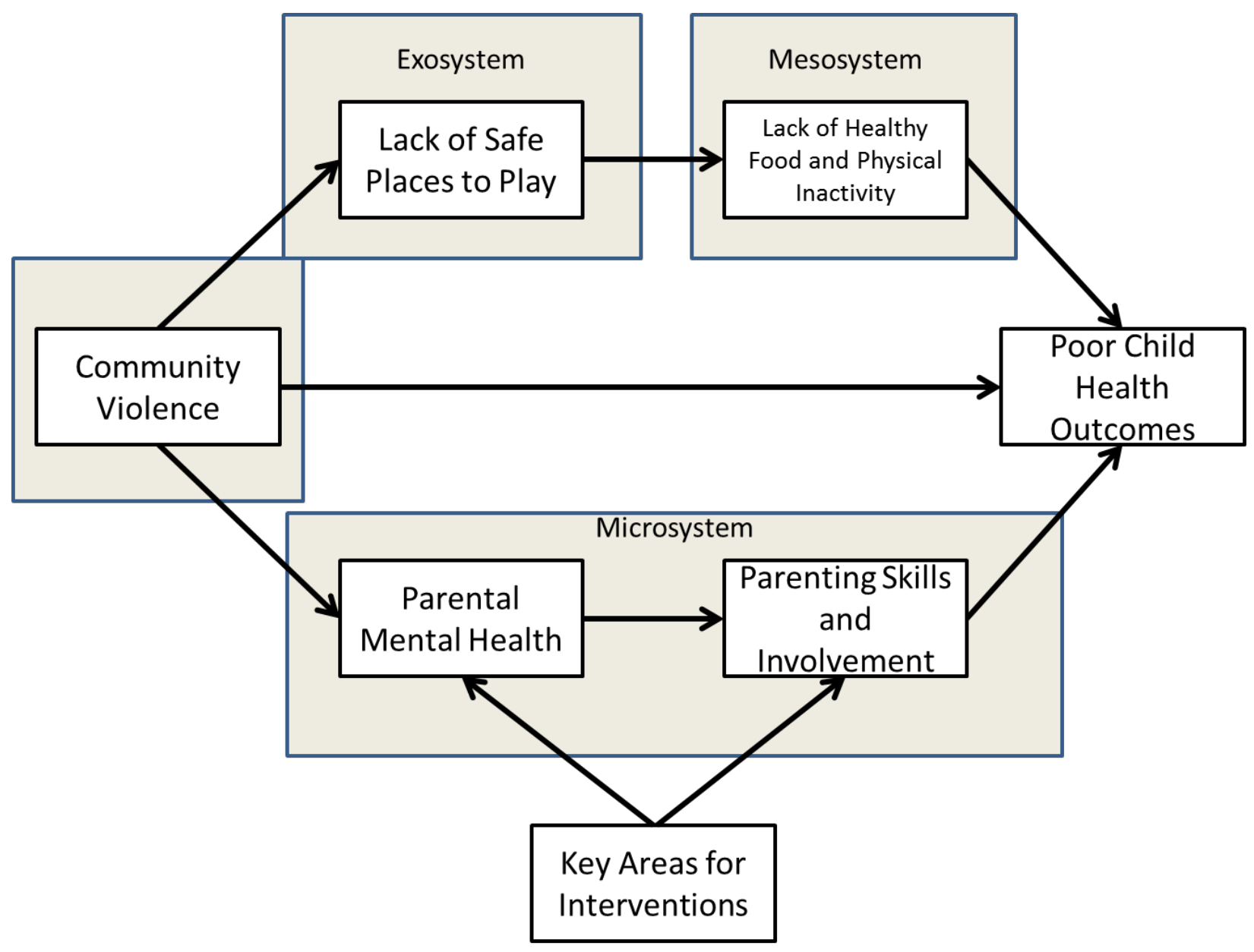

Figure 1. Conceptual model depicting respondents' perceptions of community level changes influencing children's health and priority areas for child health interventions.

Community violence was a prominent issue within the exosystem (social context) that reduced the spaces children have for outdoor physical activity and play (exosystem) and affected parental mental health (microsystem). According to respondents, compromised mental health of parents adversely affects their parenting skills, as manifested through parental disengagement and/or hostility. These factors were perceived to affect children's health and wellbeing, including child obesity. Prioritized points of intervention were parental mental health, skills and involvement - positioning parenting as essential to the health of children. There are interactions between the various constructs highlighted by respondents. The following demonstrates how respondents conceptualized the effect of environmental factors on children's health.
Obesity was identified as a priority area for children's health and as an issue that has been increasing within the target community. Many participants identified contextual factors that may influence this outcome, such as a lack of healthy food options, safe places to play outside, and engagement in physical activity. Additionally, it appears that various contextual factors interact and serve as contributors to childhood obesity. For instance, many parents indicated that children were not participating in the recommended amounts of physical activity. Concomitantly, they mentioned their own fear for allowing their children to play outside due to high levels of community violence. Some parents indicated that they would prefer for their children to remain indoors rather than play outside in an unsafe environment. The theme of community violence was particularly pervasive throughout all of the focus groups, and numerous participants were victims of community 
violence. For example, one respondent was shot in her own home by a stray bullet while she was holding her child; others recounted witnessing acts of violence within their communities.

Community violence was positioned as an underlying factor or determinant related to another priority area that parents identified - poor mental health and coping. Due to the heightened incidence and increased exposure to community violence, parents reported that their children were having difficulty coping and did not have the emotional capacity to deal with the trauma of community violence. Chronic adversity has deleterious effects on children's brains and socio-emotional development, especially during the stages of infancy and toddlerhood. For example, chronic exposure of children to stress (e.g., community violence) activates hormones involved in the stress response (i.e., cortisol) (National Scientific Council on the Developing Child, 2005/2014). Sustained activation of the stress response system may negatively alter structures in the brain that support learning and memory (Lupien et al., 2009). The consequences of adversity experienced during childhood are not limited to physical and cognitive outcomes for children; young children with repeated exposure to adversity may, in adolescence and adulthood, be at heightened risk for engaging in problem behaviors such as substance abuse and criminal activity (Koskenvuo \& Koskenvuo, 2015).

Juxtaposed with the mental health challenges of children that resulted from exposure to community violence, parents also reported their own mental health difficulties; depression was particularly salient. However, respondents were fairly dismissive of the need to seek treatment. This attitude was reinforced by individuals within their immediate support networks. This is particularly problematic for children's health and well-being due to the inhibitory nature of depressive symptoms in the establishment of strong nurturing bonds between a depressed parent and his/her children - an essential component of quality parenting. Depressed parents are more likely to engage in harsh parenting strategies, display a flat affect, and reduce interaction with their children (Jacob \& Johnson, 1997; Landman-Peeters, Ormel, Van Sonderen, Den Boer, Minderaa, \& Hartman, 2008). In view of the disparity in seeking treatment for mental health symptoms among African American women (Ward, Clark, Heidrich, 2009), the present findings support the need for interventions that include culturally tailored education to promote resilience as well as seeking treatment when needed.

In reference to contextual factors affecting children's health, most participants highlighted parenting. Respondents cited poor parenting as the most noteworthy barrier to improving child health outcomes. A sense of apathy for their children's health and well-being dedicated to their own personal affairs were the driving forces that resulted in disengaged parents. With poor parenting and involvement identified as the most robust obstacle for children's optimal health, quality parenting was the most frequently proposed solution. This finding aligns with results from resiliency research, which posits that support from a caring parent promotes resilience in children and serves as a protective factor that may mitigate the negative effects of adverse environmental settings. Therefore, addressing parenting skills and knowledge should be a component of programs aimed at improving health outcomes for children.

A macro-level solution for improving children's health was building social capital within the community and creating constructive activities for children. Respondents were particularly nostalgic for their own childhoods when they experienced a stronger sense of connectedness and involvement. Mutual respect and accountability were cited as values that need to be strengthened in the community to improve the health and well-being of children. This sense of community could offset community violence and aid in the creation of safer neighborhoods that are resourced with activities, facilities, and organizations that support the active, positive engagement of children.

Without an understanding of the complex interplay of environmental factors that influence the child health priority areas identified by community residents, proposed solutions may be incomplete and less effective. The ability to tailor programming efforts is enhanced when practitioners have an understanding of the root causes of health disparities. The results of this study show that, among community members, there is a recognition that addressing environmental factors and parenting are essential to efforts promoting health of children. Furthermore, the findings suggest that quality parenting is a public health is related to children's health and well-being and that this view is shared by the at-risk community.

Results from this study highlight the importance of utilizing a holistic approach toward improving children's health. Given the various contextual factors that influence child health outcomes, programs should address the targeted outcomes along with influential environmental factors related to those outcomes. Lastly, these findings point to the need for policies that support implementation of comprehensive parenting programs that address children's health in urban, minority populations. To address the contextual factors that affect children and families, structural changes are required. Only new policies and new legislation can provide these.

The CBPR approach used in this formative phase of intervention development will be fundamental to anticipated buy-in towards improved recruitment and sustained retention. Among the tenets of CBPR is that, to conduct effective public health research, investigators must invest the time and resources in partnerships with communitybased organizations and neighborhood residents who are gatekeepers to establishing and maintaining community buy-in, ownership, and sustainability. Due to residents' heightened awareness of community systems affecting children's health, aligning community-identified child health priorities with established epidemiological health risks should enhance the efficacy of interventions aimed at improving health outcomes and the social determinants of health for urban minority children. 
The current results provide insight in regard to viewpoints of urban minority parents on contextual factors that may affect children's health; however, the generalizability of findings may not extend beyond African American parents. Further, over $75 \%$ of the current sample was comprised of female participants, and the themes that surfaced may be more reflective of the perspective of mothers rather than fathers. The recruitment strategy may have reduced the generalizability of research findings due to convenience sampling. It is possible that parents who volunteered to participate in the focus group discussions were highly active in their respective communities, and the findings may not reflect the voices of residents less inclined to engage in community-based activities.

\section{CONCLUSIONS}

Gaining community insight on comprehensive solutions for child health disparities is essential for the development of innovative programs that promote children's health. The current study reinforce the understanding of the function of social determinants of health in predicting health outcomes for children and emphasizes the fundamental role of parenting. In regard to children's health, quality parenting is a public health issue that should be considered in holistic prevention and intervention efforts. As practitioners and researchers endeavor to reduce health disparities among children residing in adverse environmental settings, collaborations with community residents may provide solutions that are more effective and resonate better with potential program participants.

\section{Acknowledgements}

Funding from the National Institute of Minority Health and Health Disparities (NIMHD) Grant Number 5R24MD008084-03, the NIMHD Grant Number 5P20MD006881-04, the NIMHD Grant Number 5U54MD008173-03, and the Centers for Disease Control (CDC) and Prevention Health Promotion and Disease Prevention Research Center Grant Number 1U58DP005945-01. The content is solely the responsibility of the authors and does not necessarily represent the official views of NIMHD or the CDC. We would also like to acknowledge the Accessible Resources for Community Health board and Smart and Secure Children Advisory board for their guidance and support during this research process.

\section{References}

Administration for Children, Youth and Families' Children's Bureau. (2012). Promoting Protective Factors for In-Risk Families and Youth: A Brief for Researchers. Retrieved from http://www.dsgonline.com/acyf/PF_Research_Brief.pdf.

Bronfenbrenner, $\mathrm{U}$. The ecology of human development:

Experiments by nature and design. London; 1979: Harvard University Press.

Cargo, M., \& Mercer, S. The value and challenges of participatory research: Strengthening its practice. Annu Rev Public Health, 2008, 29, 325-350.

Chan, S. Social competence of elementary-school children: relationships to maternal authoritativeness, supportive maternal responses and children's coping strategies. Child Care Health Dev, 2011,37(4), 524-532.

Children's Bureau. Promoting Protective Factors for In-Risk Families and Youth: A Brief for Researchers; 2012.

Darling, N., \& Steinberg, L. Parenting style as context: An integrative model. Psychol Bull., 1993, 113(3), 487-496.
Davidov, M., \& Grusec, J. Untangling the links of parental responsiveness to distress and warmth to child outcomes. Child Dev, 2006, 77(1), 44-58.

Fiscella, K., \& Kitzman, H. Disparities in academic achievement and health: The intersection of child education and health policy. Pediatr, 2009, 123(3), 1073-108.

Jacob, J., \& Johnson, S Parent-child interaction among depressed fathers and mothers: Impact on child functioning. J Fam Psychol, 1997, 11(4), 391-409.

Jagosh, J., Macaulay, A., Pluye, P., Salsberg, J., Bush, P., Henderson, J., et al. (2012). Uncovering the benefits of participatory research: Implications of a realist review for health research and practice. Milbank Q, 2012, 90(2), 311-346.

Jones, L., \& Wells K. Strategies for academic and clinician engagement in community-partnered research. JAMA, 2007, 297(4):407-410.

Koskenvuo, K., \& Koskenvuo, M. Childhood adversities predict strongly the use of psychotropic drugs in adulthood: a population-based cohort study of 24284 Finns. J Epidemiol Community Health, 2015, 69(4), 354-360.

Krueger, R. Moderating focus groups. Volume 4. Thousand Oaks, CA; 1998, Sage Publications, Inc.

Lupien, S., de Leon, M., de Santi, S., Convit, A., Tarshish, C., Nair, N., ... \& Meaney, M. Cortisol levels during human aging predict hippocampal atrophy and memory deficits. Nature Neurosci, 1998, 1(1), 69-73.

Lupien, S., McEwen, B., Gunnar, M., \& Heim, C. Effects of stress throughout the lifespan on the brain, behaviour and cognition. Nat Review Neurosci, 2009, 10(6), 434-445.

Landman-Peeters, K., Ormel, J., Van Sonderen, E., Den Boer, J., Minderaa, R., \& Hartman, C. Risk of emotional disorder in offspring of depressed parents: Gender differences in the effect of a second emotionally affected parent. Depress Anxiety, 2008, 25(8), 653-660.

Masten, A., Best, K., \& Garmezy, N. Resilience and development: Contributions from the study of children who overcome adversity. Dev. Psychopathol, 1990, 2, 425-444.

Mistry, R., Benner, A., Biesanz, J., Clark, S., Howes, C. (2010). Family and social risk, and parental investments during the early childhood years as predictors of low-income children's school readiness outcomes. Early Child Res. Q., 2010, 25(4), 432-449.

Monaghan, M., Horn, I., Alvarez, V., Cogen, F., \& Streisand, R. Authoritative parenting, parenting stress, and self-care in preadolescents with type 1 diabetes. J Clin Psychol Med Settings, 2012, 19(3), 255-261.

National Institute for Health Care Management. Reducing Health Disparities among Children: Strategies and Programs for Health Plans, 2007.

National Scientific Council on the Developing Child. (2005/2014). Excessive Stress Disrupts the Architecture of the Developing Brain: Working Paper 3. Updated Edition. Retrieved from www.developingchild.harvard.edu

Ogden, C., Carroll, M., \& Flegal K. High body mass index for age among US children and adolescents, 2003-2006. JAMA, 2008, 299(20), 2401-2405.

Ogden, C., Troiano, R., Briefel, R., Kuczmarski, R., Flegal, K., \& Johnson, C. Prevalence of overweight among preschool children in the United States, 1971 through 1994. Pediatr, 1997, 99(4), E1.

Rossen, L. Neighborhood economic deprivation explains racial/ethnic disparities in overweight and obesity among children and adolescents in the USA. J. Epidemiol. Community Health, 2014, 68(2), 123-129.

Rutter, M. Resilience in the face of adversity: Protective factors and resistance to psychiatric disorder. Br. J. Psychiatry, 1985, 147(6), 598-611.

Sandelowski, M. Sample size in qualitative research. Res. Nurs. Health, 1995, 18(2), 179-183. 
Seifer, S. Building and sustaining community-institutional partnerships for prevention research: Findings from a national collaborative. J. Urban Health, 2006, 83(6), 989-1003.

Strauss A. \& Corbin J. Basics of Qualitative Research: Techniques and Procedures for Developing Grounded Theory, 2nd edn. Sage Publications, Thousand Oaks, CA; 1998, USA.

Taveras E., Gillman M., Kleinman K., Rich-Edwards J., RifasShiman S. Reducing racial/ethnic disparities in childhood obesity: The role of early life risk factors. JAMA Pediatrics,167(8), 731-738.

U.S. Census. (2006-2010). Community survey. Retrieved from http://factfinder.census.gov/faces/tableservices/jsf/pages/product view.xhtml?src=bkmk.
U.S. Department of Health and Human Services. Office of Disease Prevention and Health Promotion.Healthy People 2020.

Washington, DC. Available at

https://www.healthypeople.gov/2020/About Healthy-People. Accessed March 31, 2015

Ward E., Clark L., Heidrich S. African American women's beliefs, coping behaviors, and barriers to seeking mental health Services. Qual health res, 2009,19(11):1589-1601.

Whittaker, J., Jones Harden, B., See, H., Meisch, A., \& Westbrook, T. Family risks and protective factors: Pathways to Early Head Start toddler's social-emotional functioning. Early Child Res. Q., 2011, 26(1), 74-86. 